\title{
ST radar observations of atmospheric waves over mountainous areas: a review
}

\author{
J. Röttger \\ Max-Planck-Institut für Aeronomie, Max-Planck-Str. 2, D-37191 Katlenburg-Lindau, Germany \\ e-mail: roettger@linmpi.mpg.de
}

Received: 19 January 2000 / Revised: 30 March 2000 / Accepted: 12 April 2000

\begin{abstract}
Lee and mountain waves are dominant dynamic processes in the atmosphere above mountain areas. ST VHF radars had been intensively used to investigate these wave processes. These studies are summarized in this work. After discussing features of long-period quasi-stationary lee waves, attention is drawn to the frequent occurrence of freely propagating waves of shorter periods, which seem to be more common and characteristic for wave processes generated over mountainous areas. Characteristics of these waves such as their relation to the topography and background winds, the possibility of trapping by and breaking in the tropopause region and their propagation into the stratosphere is investigated. These orographically produced waves transport energy and momentum into the troposphere and stratosphere, which is considered an important contribution to the kinetic energy of the lower atmosphere. The occurrence of inertia-gravity waves in the stratosphere had been confused with lee waves, which is discussed in conclusion. Finally further questions on mountain and lee waves are drawn up, which remain to be solved and where investigations with ST radars could play a fundamental role.
\end{abstract}

Key words: Meteorology and atmospheric dynamics (Middle atmosphere dynamics; Waves and tides; Instruments and techniques)

\section{Introduction}

Since the invention of MST (mesosphere-stratospheretroposphere) VHF (very high frequency) radars by Woodman and Guillen (1974) these systems had been very successfully applied to studies of atmospheric gravity waves in the lower and middle atmosphere. These radars even appear to be optimum tools for such investigations compared to some other ground-based instruments. The major advantage of VHF radars is their capability to measure continuously the threedimensional velocity vector with a time resolution better than a minute and a best height resolution of about hundred meters. These adapt properly to typical parameters of atmospheric gravity waves.

Although contemporary MST VHF radars (Röttger and Larsen, 1990; Hocking, 1997a, b) do not have the sensitivity to observe events in altitudes between about $30 \mathrm{~km}$ and $60 \mathrm{~km}$, and detect only intermittent events in the mesosphere, they are most suitable for studies of the troposphere and the lower stratosphere. Many case studies of ST (stratosphere-troposphere) radar observations of gravity wave generation by shear and convective instability have been performed (Fritts and Rastogi, 1985). The propagation and dissipation of these waves and the corresponding energy dissipation and momentum fluxes have been studied explicitly for lee or mountain waves (Nastrom and Fritts, 1992; Prichard and Thomas, 1993). Many studies proved that gravity waves are major dynamic processes which affect the small-scale structure, such as turbulence (Hocking, 1985, 1996), as well as the large-scale dynamics, namely the global circulation of the atmosphere (Palmer et al., 1986). The ST radar technique has been utilized also for wind profiler applications in operational meteorology (Lafaysse, 1994). Here we concentrate on scientific studies of atmospheric waves with VHF radars.

Other ground-based systems than VHF radars, which are employed for middle and upper atmosphere studies (Dieminger et al., 1996), have more limited capabilities for gravity wave observations, such as: (a) meteor radars, which obtain information on winds and temperature over longer averaging periods; (b) MF radars, measuring winds, or incoherent scatter radars, measuring electron density and winds, have resolution or sensitivity limits, respectively. MF and meteor radars on the other hand, are usually operated continuously and, thus, provide most valuable statistical 
information; (c) lidars are mostly restricted to nighttime observations and can exceptionally measure velocities with sufficient time resolution, and can also measure temperature and minor constituents profiles; (d) airglow spectrometers, which are confined to nighttime, too, cover only a limited altitude range near the mesopause, but they can provide a two-dimensional image. The latter can also be achieved with visual or photographic methods, which image larger scale wave structures in the mesosphere (noctilucent clouds, NLC) and in the stratosphere (polar mesosphere clouds, PSC) in polar regions.

These methods mentioned apply to the middle atmosphere, whereas we will concentrate in this article on observations of waves in the lower atmosphere, i.e., the troposphere and stratosphere. It can be very valuable for this purpose to combine VHF radar observations with lidar (Mitchell et al., 1994), with aircraft and balloon (Caccia et al., 1997a) and with synoptic weather information (Rechou et al., 1998), although we will show that also VHF radar observations on their own can provide most valuable information on wave features in the atmosphere.

Optical imaging in two dimensions of tropospheric and stratospheric waves has also been done. The observations of the PSC are an obvious example for this (Enell et al., 1999). Imaging at larger dimensions cannot be furnished by MST radars unless a network of radars is employed. However, ST VHF radars in a suitable configuration, deliver height profiles of many essential parameters of gravity waves, such as the velocity amplitude in three dimensions, phase velocities and wavelengths, the Doppler shift of gravity waves due to the mean wind and the deposition of energy and momentum. In order to measure such wave characteristics, co-planar antenna-beam directions (Vincent and
Reid, 1983), a set of closely spaced radars (e.g., Ecklund et al., 1985), post-beam-steering (e.g. Röttger and Ierkic, 1985), and multiple antenna beam directions can be employed (e.g., Czechowsky and Rüster, 1997).

It is still difficult even so, to trace gravity waves which are propagating horizontally over larger distances, since the MST radars observe only a limited region overhead their location. This limitation is principally not a hindrance when studying quasi-stationary waves, such as mountain or lee waves, which are generated by a steady wind blowing over a corrugated terrain. Figure 1 shows the undulation of streamlines of air flow, which is distorted by an obstacle on the ground, i.e., a mountain ridge (Scorer, 1997). Such a distortion can propagate from the ground upwards into the troposphere and middle atmosphere. The parameters of such a lee wave depend on the wind and temperature profile, and the topography where they are generated. These waves can often be observed visually from the ground as typical periodical and lense-like cloud structures (e.g., Scorer, 1978, 1997) and from space as long wave trains (e.g., Eckermann and Preusse, 1999). The lenticularis clouds form in the cold phase of the lee waves (thick sections of the stream-lines lines in Fig. 1). It can be noticed in Fig. 1 that radiosonde balloons, when carried by the background wind, pass through different phases of such a wave. Using radiosonde data alone will consequently make interpretation of the dynamical processes, governing these waves, quite tedious.

We have to add here that lee waves, which propagate into the polar stratosphere can produce PSC. Chemical processes in these clouds are causing destruction of ozone (Cariolle et al., 1989; De Rudder et al., 1996; Tie et al., 1996). It is not the purpose of this study to discuss ozone destruction, but it is noticed that ST radar observations in polar regions contribute to the under-

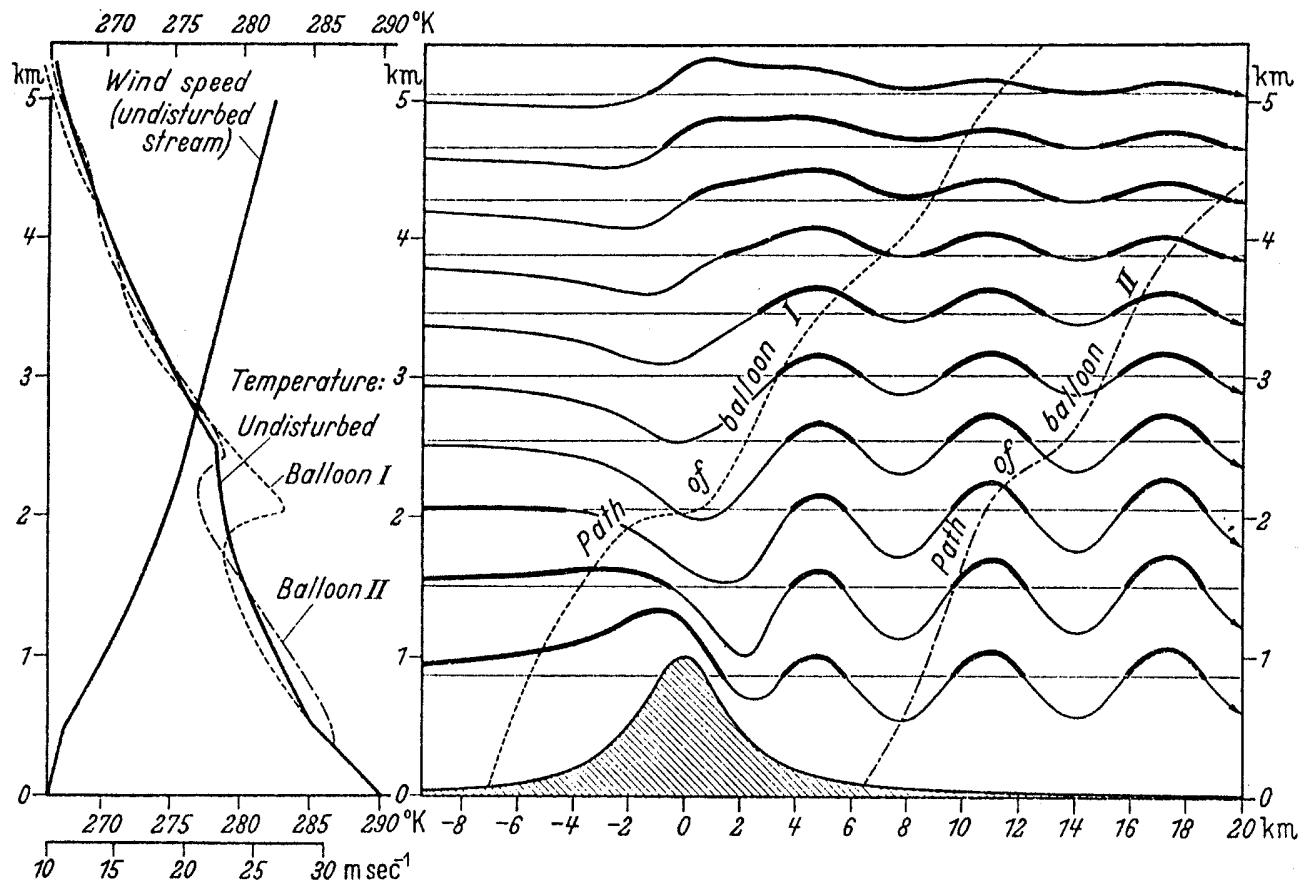

Fig. 1. Air flow over a mountain ridge generating a train of lee waves aloft. The change of phase and amplitude with altitude is caused by a change of the mean wind and temperature, as shown in the left-hand panel (from Scorer, 1997, Copyright John Wiley) 
standing of the dynamical processes (Rechou et al., 1999), which are responsible for the formation of a certain kind of PSC. Lidar observations are also most valuable for such studies of PSC, since they detect scatter from the ice particles in the PSC (Fricke et al., 1998) and further deliver temperatures (Hansen and Hoppe, 1997; Mehrtens et al., 1997). The combination of ST radars, providing three-dimensional wind profiles, and lidar furnishing temperatures and PSC structures, is highly advisable for such studies in Arctic regions.

In this paper we will describe some ST radar observations of orographically generated waves and how they can contribute further to the understanding of such impressive wave features. Several ST radars have been used for this purpose, in particular the ones in regions of elevated orography apt to excite mountain lee waves.

For example, ST radar observations of mountain or lee waves were made in the Harz mountains, Germany (Röttger et al., 1981; Schlüter, 1993), near the Alps in France (Ecklund et al., 1985; Ralph et al., 1992; Caccia et al., 1997b), close to the Rocky Mountains in Colorado, USA (Ecklund et al., 1982; Nastrom et al., 1987), in the mountain terrain of Wales near Aberystwyth, UK (Prichard et al., 1995), on the island of Puerto Rico (Hines, 1988) although such waves were later identified as inertia-gravity waves, observations of mountain waves close to the Andes in Peru (Liziola and Balsley, 1997), in Taiwan (Röttger et al., 1990), in Sondrestromfjord, Greenland (Mikkelsen, personal communication, 1999), over islands in the equatorial Pacific (Balsley and Carter, 1989), at the northern Scandinavian mountain ridge in Andoya, Norway (Hoffmann et al., 1999), and Kiruna, Sweden (Stebel et al., 1997), and most recently on the island of Spitzbergen (Röttger, 2000).

Although not always immediately evident in wind profiles measured over uneven terrain, it has to be assumed that such orographically generated waves exist in many observational data sets. Thus, certain precautions should apply in the interpretations of larger-scale features in the wind, such as those applied to wind profiling (Lafaysse, 1994). However, we are not discussing here the effects of mountains on meso-scale and synoptic-scale flows (Sun and Chern, 1993; Takayabu et al., 1996), but we notice that mountain waves have an effect on meso-scale stratospheric temperature anomalies (Leutbecher and Volkert, 1996) and on winds in the middle atmosphere (Bacmeister, 1993). Studies have also been performed to distinguish slowly varying mountain and lee waves from inertia gravity waves (Cornish and Larsen, 1989; Cho, 1995) or vortical modes (Worthington and Thomas, 1998).

Here, we first describe an early example of wave observations with the SOUSY-VHF-Radar, assumed to be a feature of a lee wave, and add a short description of lee wave generation and propagation over the Harz mountains. Thereafter we will try to summarize some pertinent lee and mountain wave observations made i.e., with the Aberystwyth VHF Radar in Wales, UK, ST wind profilers in southern France, and the VHF radars ALOMAR SOUSY in Andoya, Norway and ESRAD operated by ESRANGE in Kiruna, Sweden. We also add a short discussion of long-period waves, which were observed at the MU radar in Japan and the Arecibo Observatory, since it was presumed that the latter could be mountain waves.

This work is not to be regarded as providing a fully concise examination and a critical assessment of mountain/lee wave investigations. It essentially confines itself to a summary of the radar observations and the corresponding interpretations. It is somewhat dominated by observations with the Aberystwyth VHF radar since most of the investigations of lee waves were done with this instrument. The author has tried to abstain from combining the results, which are obtained at many different locations and under quite diversified atmospheric conditions, into an ultimately comprehensive depiction and interpretation of lee wave characteristics.

\section{Quasi-stationary lee waves detected by ST radar}

Wind profiles observed with ST radar often show a wavelike pattern with vertical wavelength of a few kilometers. An example of a longer lasting event is shown in Fig. 2, which presents height profiles of wind speed $U$ and direction $\alpha$. This snapshot of a longer data series was an averaged over $27 \mathrm{~min}$, but it shows the essentials. Superimposed on the background wind was an oscillating pattern with a perturbation of wind speed and direction with height. Röttger et al. (1981) did not attribute this pattern to a synoptic or meso-scale disturbance but assumed that such a perturbation is a signature of a gravity wave. Given the mountainous location of the SOUSY VHF Radar, it was supposed
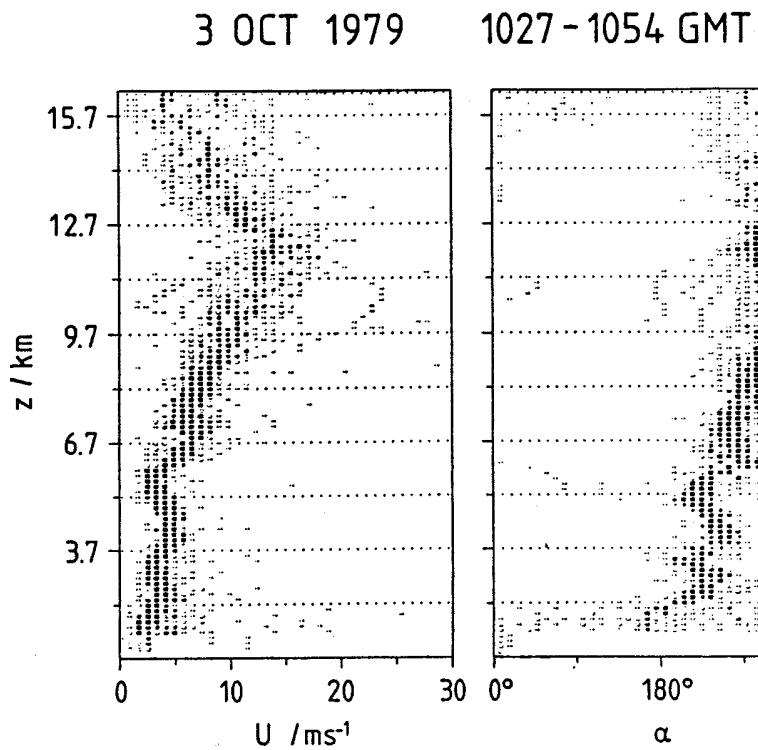

Fig. 2. Profiles of wind speed $U$ and direction $\alpha$ measured with the SOUSY-VHF-Radar in the spaced antenna mode (after Röttger and Czechowsky, 1981). Individual data points were obtained during an analysis period of $40 \mathrm{~s}$. The scatter of these distributions results from natural variability of the wind, except at altitudes around $10-11 \mathrm{~km}$ and above $14 \mathrm{~km}$, where the signal-to-noise ratio was small 
that such a wave could be a mountain or lee wave, which was generated by the low-level wind blowing around a rather local obstacle, which are the Harz mountains where the radar observations were made. To understand all details of the horizontal wind variations a threedimensional model would have to be applied, especially since the observed wind vector changed with height. To investigate whether these wind variations could have been features of lee waves, a less sophisticated twodimensional model was assumed to be sufficient. For this purpose Röttger et al. (1981) used the mean wind speed profile of Fig. 2 and the temperature profile from a radiosonde, about $100 \mathrm{~km}$ northeast of the radar location. The wind profile consists of a component $U_{a}$, which increases almost linearly with height, and a superimposed periodic variation. In Fig. $3 \mathrm{a}$ the mean profile deduced from Fig. 2 is shown, and Fig. $3 b$ shows the relative amplitude of the superimposed periodic variation with height.

These results have been compared by Röttger et al. (1981) with a two-dimensional lee wave model, following Scorer (1978). This model is based on the theory of a wave created over a corrugated bottom boundary, i.e., a mountainous surface. It is also assumed that this wave is reflected below the tropopause (about $12 \mathrm{~km}$ ), which results in a standing or trapped wave. This is justified, since we do not see a clear wave pattern in the lower stratosphere (above $12 \mathrm{~km}$ ). Scorer's (1972) theory yields the displacement of stream lines representing the lee wave. The parameter deduced from these radar observations are the wind variations, which should have the same vertical wavelength variations as the displacement. The vertical wavelength is obtained from the Scorer parameter 1 (Eq. 2.76 of Smith, 1979; Ralph et al., 1992), which supplies an elementary description of a mountain or lee wave:
$l^{2}=N^{2} /(c-U)^{2}-1 /(c-U) \cdot \mathrm{d}^{2} U / \mathrm{d} z^{2}$

It depends on the wind speed $U$, the second derivative of $U$ with height $z$ and the static stability, given by the Brunt-Väisälä frequency $N$. It also depends on the horizontal phase speed $c$ of the waves as observed by the radar. The dispersion relation yields the vertical wave number

$\mathbf{k}_{z}^{2}=l^{2}-k_{h}^{2}$

where $\mathbf{k}_{h}=\left(k_{x}, k_{y}\right)$ is the horizontal wave vector. For quasi-stationary long period waves $c=0$ and $l^{2} \gg k_{h}^{2}$, which means that the Scorer parameter determines the vertical wavelength $\lambda_{z}=2 \pi / l$. In realistic cases the quantities $U$ and $N$ vary with height and time, which results in a change of the vertical wavelength with height and time, respectively. Since a wavelength is not properly defined when it varies within one wave period, it is more appropriate to use the term Scorer parameter rather than vertical wavelength. Variations of $U$ and $N$ with height are the reason why the phase and amplitude of the lee wave in Fig. 1 changes with height (Scorer, 1997).

The profiles of $N$ can be deduced from temperature measurements with radiosondes and those of $U$ from the ST radar measurements. Using these parameters and a simple Gaussian-shape model of the mountain area surrounding the radar, Röttger et al. (1981) calculated the variation of the relative displacement amplitude of stream lines with altitude (Fig. 3c), which compares well with the observed relative deviation of the horizontal wind from the mean wind. Thus, it was, thought that these wavelike variations of the wind (Fig. 3a, b) are consistent with a quasi-stationary trapped mountain lee wave. On the other hand, the wind rotation with height might also be a sign for inertia-gravity waves. This is discussed further in Sect. 5.
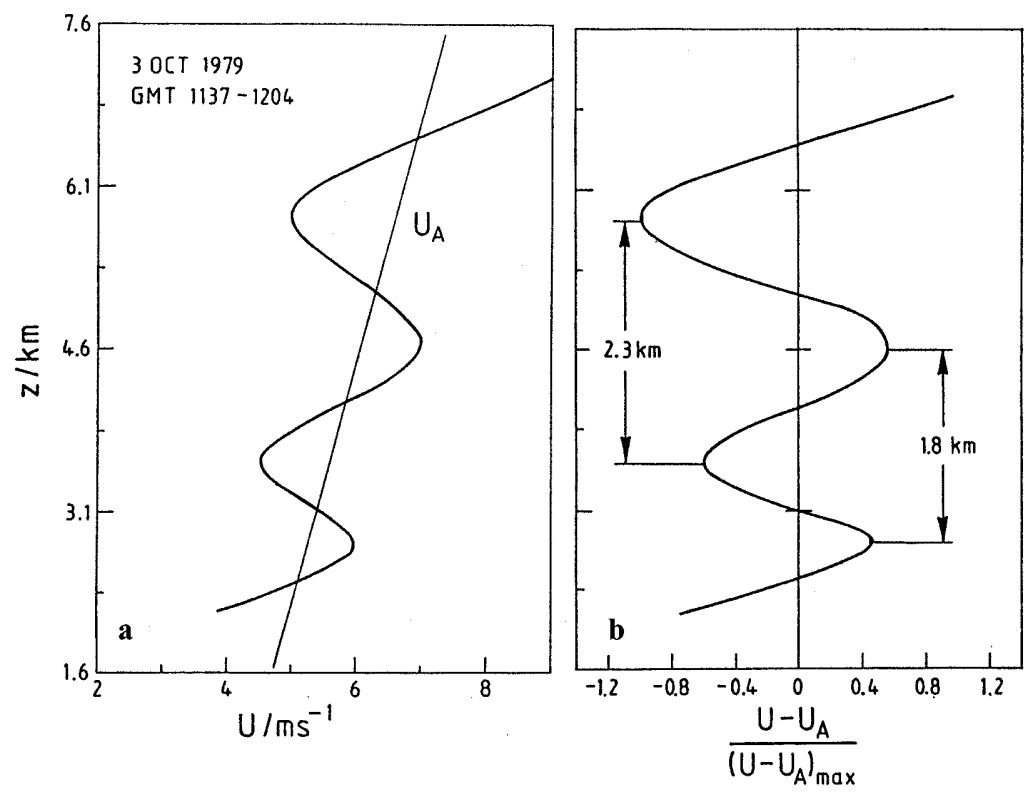

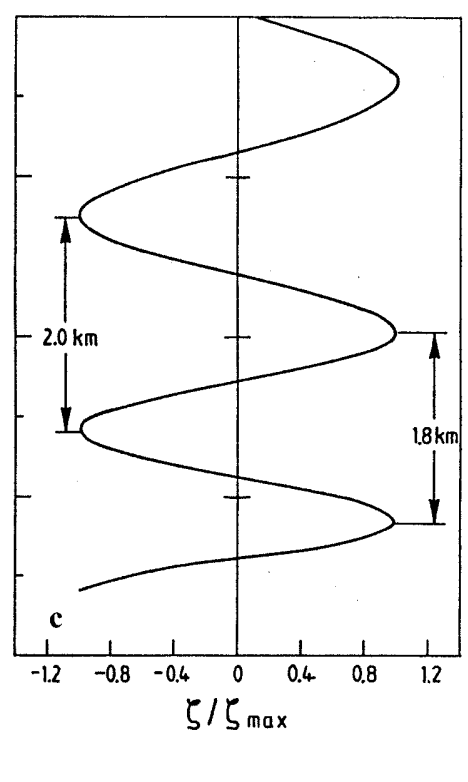

increase $U_{a} ; \mathbf{c}$ relative displacement of stream lines calculated from the model (after Röttger et al., 1981)
Fig. 3a-c. Height profiles of: a averaged wind speed $U$ deduced from Fig. 2, the straight line shows the linear increase of mean wind speed $U_{A}$ with height $z$; b relative deviation of wind speed from linear 
The vertical velocity is a very sensitive quantity to detect lee waves as can be recognized from the stream lines in Fig. 1. There are many results proving that the vertical velocity can be measured with ST radar, although several precautions have to be adopted. In Fig. 4 the profiles of radar observations with vertically pointing antenna beam are shown (from Röttger et al., 1990). The center panel depicts the radial velocity $w$ and the right-hand panel the angle of arrival $\delta$ of the radar signal. These two quantities $w$ and $\alpha$ are correlated. The reason is that the radial velocity is not the pure vertical velocity, but contains a component of the horizontal wind, if the angle of arrival is offset from the zenith. The angle of arrival comprises an estimate of the inclination of scattering or partially reflecting layers of the radar refractive index. These layers are assumed to be represented by the stream lines, which are strongly undulating in lee wave events (Fig. 1), i.e., inclined against the horizontal plane. In such cases projections of horizontal wind components add to the vertical wind component. Van Baelen et al. (1991) note that if the scatterers and the airflow are tilted, then there is a tendency for the angle of arrival to approach perpendicularity with the 3dimensional wind vector. Then the magnitude of the vertical wind component is reduced rather than increased. By combining the measurements of radial velocity, horizontal velocity, angle of arrival and anisotropy an improved estimate of the vertical velocity can be obtained. It was conjectured that the periodic variation of radial velocity and angle of arrival (equivalent to the tilt or inclination of the radar scattering layer), shown in Fig.4, are due to a mountain lee wave. Whereas tilting of scattering or partially reflecting layers had initially been investigated with the spatial radar interferometry (Röttger et al., 1990), it was shown by Worthington et al. (1999), that the Doppler beamswinging (DBS) method with multiple antenna beams can also be applied, since it allows us to deduce the tilt from the variation of the aspect sensitivity (anisotropy and anisometry of scattering layers) as function of azimuth.

We have to note here, however, that the DBS method can lead to uncertainties in the determination of mountain or lee-wave velocities, since the DBS antenna beams point into different phases of such waves. The combination of the radial velocities, determined with the DBS method, is usually applied to obtain the mean, synoptic-scale wind component. These results can significantly be altered in the presence of strong lee wave activity. The spaced antenna (SA) method is more suitable for such observations, since the wind is measured in just the same volume, overhead the radar (e.g., Röttger, 1981c; Hocking, 1997b).

In summary we want to state that all capabilities of an ST radar, combined with suitable supplementary observations, should be applied to achieve conclusive knowledge on lee and mountain wave features. When these precautions are taken, ST radars can yield vertical profiles of the following parameters, which are essential for lee and mountain wave studies: horizontal and vertical wind velocity, the inclination of stream line surfaces and radar reflectivity anisotropy. Much more detailed modeling work and comparisons with ST radar and complementary instruments are still necessary to understand the interaction of these processes. In the following we discuss a few further lee and mountain wave observations with other radars, in particular from the viewpoint of understanding their diversified properties at different temporal and spatial scales and their impact on dynamic meteorology of the troposphere and lower stratosphere.

\section{Orographically generated non-stationary waves}

It has been observed at different locations in the lee of mountain areas that not so many long-period or standing waves exist but short-period waves appear to dominate at certain times. The periods of these waves are frequently in the order of several ten minutes, as Fig. 5 shows for observations in the lee of the Andes in Peru (Liziola and Balsley, 1997). Figure 6 shows such an event close to the mountain area of Wales (Prichard et al., 1995), where somewhat longer periods are prevalent. The waves observed near the Andes had horizontal wavelengths of some ten kilometers and horizontal

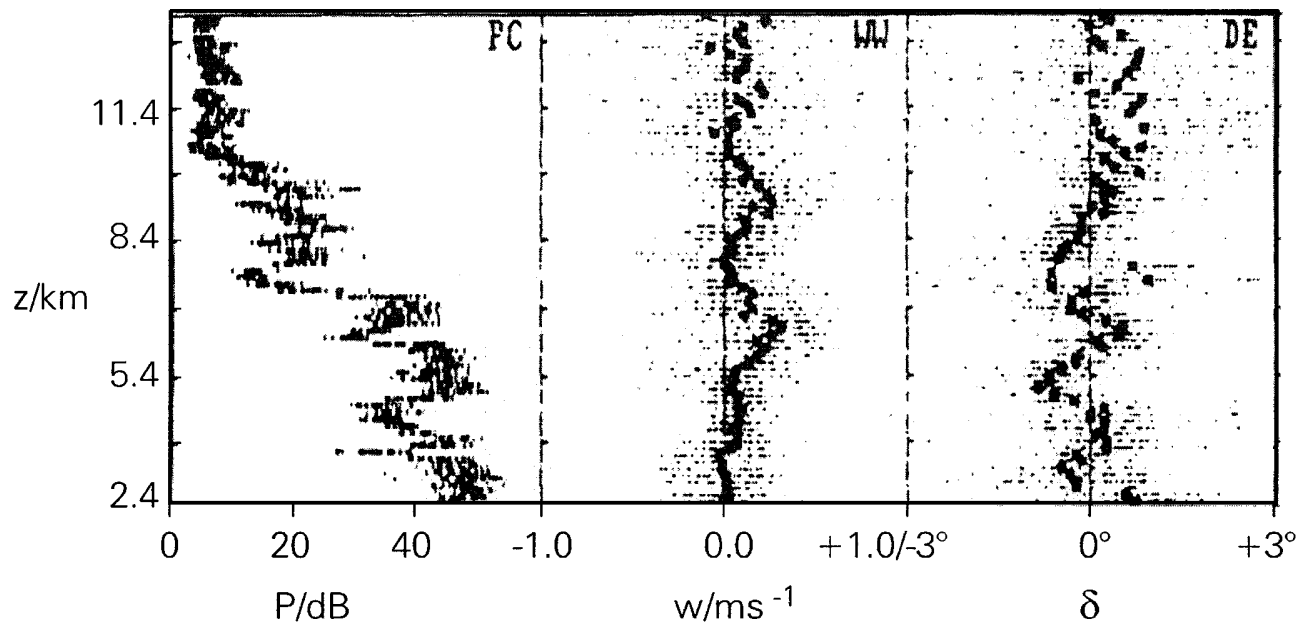

Fig. 4. Height profiles of the distributions of normalized power $\mathbf{P}$, radial velocity $w$ in vertical beam and eastward component of the angle of arrival or zenith angle $\delta$, measured with the Chung-Li VHF radar on 19 December 1988, 1711-1714 UT. Individual data were taken every $6 \mathrm{~s}$ (after Röttger et al., 1990, Copyright American Geophys. Union) 


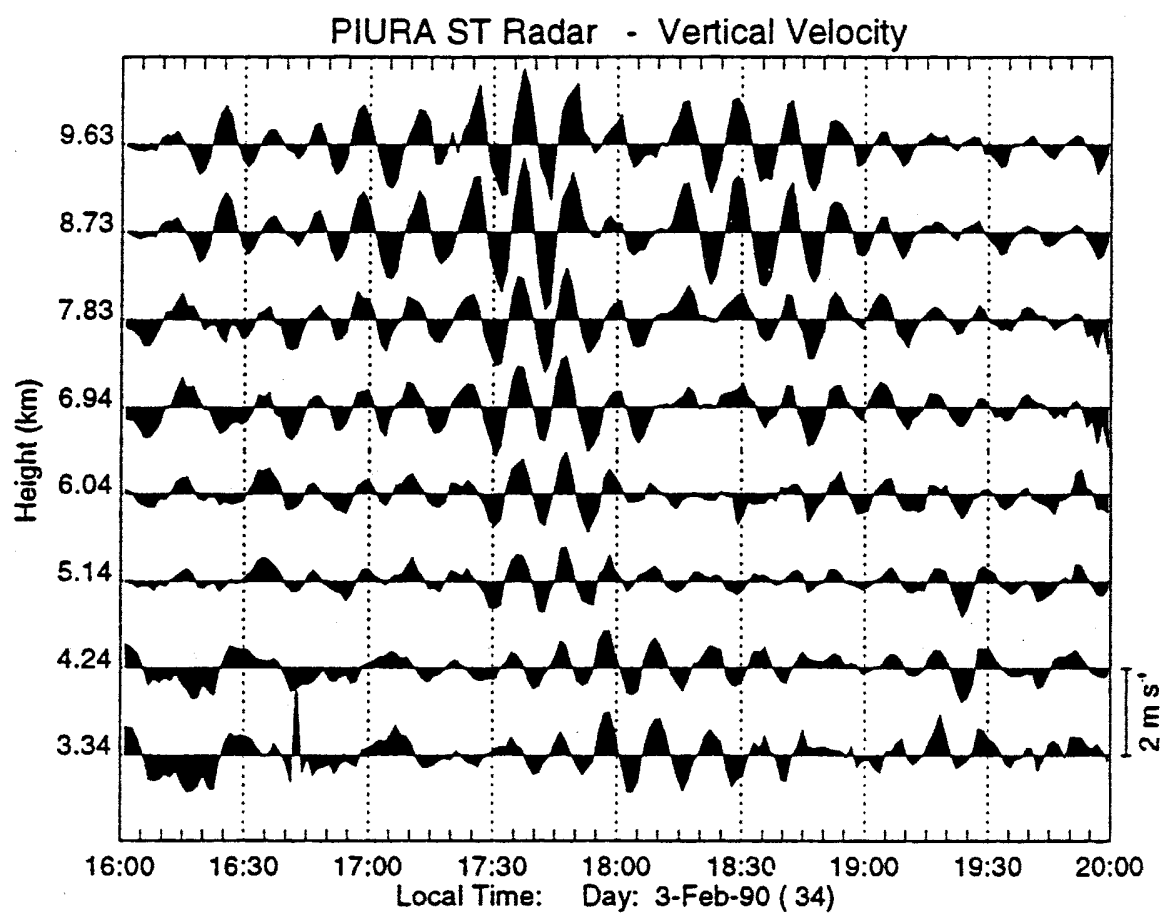

Fig. 5. Wave-like variations of velocity in the vertical antenna mode observed with the Piura ST radar wind profiler (from Liziola and Balsley, 1997, Copyright American Geophys. Union) phase speeds of some $10 \mathrm{~ms}^{-1}$ and are small- to mediumscale waves. It is obvious that this kind of wave activity depends clearly on the direction of the horizontal wind at low altitudes as e.g., Ralph et al. (1992) and Prichard et al. (1995) have shown. Figure 7 presents results of VHF radar measurements in northern Scandinavia on the windward side (Fig. 7a) and the leeward side (Fig. 7b) of the North Norwegian mountain ridge. It is quite obvious that the vertical velocities in both cases show a maximum for wind directions from northwest, which is approximately perpendicular to the alignment of the mountain ridge. Similar observations were published by Stebel et al. (1997) and Stebel and Kirkwood (1999), who showed that this directional dependence is even more pronounced when compared with low-level winds. Whether the velocity variance observed on the windward side of the ridge (Hoffmann et al., 1999) results from waves generated by the orography or by shear instability in the jetstream remains to be investigated in more detail. Care has to be taken in at least these two cases, since waves may be generated by jet stream and frontal systems (Fritts and Nastrom, 1992), which could be confused with orographically generated waves, and longer period waves are frequently found to be inertia-gravity waves (Cho, 1995; Thomas et al., 1999). This will briefly be discussed in Sect. 5.

Ecklund et al. (1985), using a system of three ST radars in the lee of the Alps in southern France, had found that similar wave oscillations as shown in Figs. 5 and 6 , decorrelate over distances of more than $5 \mathrm{~km}$. There are enhanced oscillations close to the BruntVäisälä frequency (Röttger, 1981a; Ecklund et al., 1985), which are typical for quiet periods (i.e. low wind velocities). Whether they are caused by or related to orographically generated waves remains unknown. Dur- ing active periods (strong winds) wave oscillations are no more clearly discernible, but the vertical velocity fluctuations are more than an order of magnitude stronger than those during the quiet times. This holds in particular for periods longer than several ten minutes. Similar observations were obtained with the Poker Flat MST radar in Alaska (Ecklund et al., 1981) and above the Colorado plains when the wind blows from the direction of the Rocky Mountains (Ecklund et al., 1982). Such longer period, large amplitude variations were certainly attributed to arise from quasi-stationary mountain waves. Comparisons with VHF ST radar observations in the plains of Illinois in USA (Nastrom et al., 1990) show that the wave activity in the flat land is much less notable than in the vicinity of mountains. That supports the confidence that the described results from radars in or near mountainous regions prove the orography to be a dominant excitation source. The relevance of topography as source of gravity waves has been strengthened by Nastrom and Fritts (1992).

The radar observations of atmospheric wave activity in the vicinity of mountainous regions really demonstrate that usually a spectrum of waves exists, which covers long periods of many hours to shortest periods close to or even beyond the Brunt-Väisälä frequency (e.g., Worthington and Thomas, 1998), if the waves are Doppler shifted. Considering that air flow is over a mountainous surface, which contains large and smallscale spatial components, we anticipate such a spectrum of waves to be generated. This is properly noticed in Fig. 8, which shows the components of the vertical velocity in certain period ranges of the spectrum. Similar quasi-periodic variations of the velocity measured with vertical antenna beam were observed with the SOUSYVHF-Radar, which may not necessarily be attributed to 


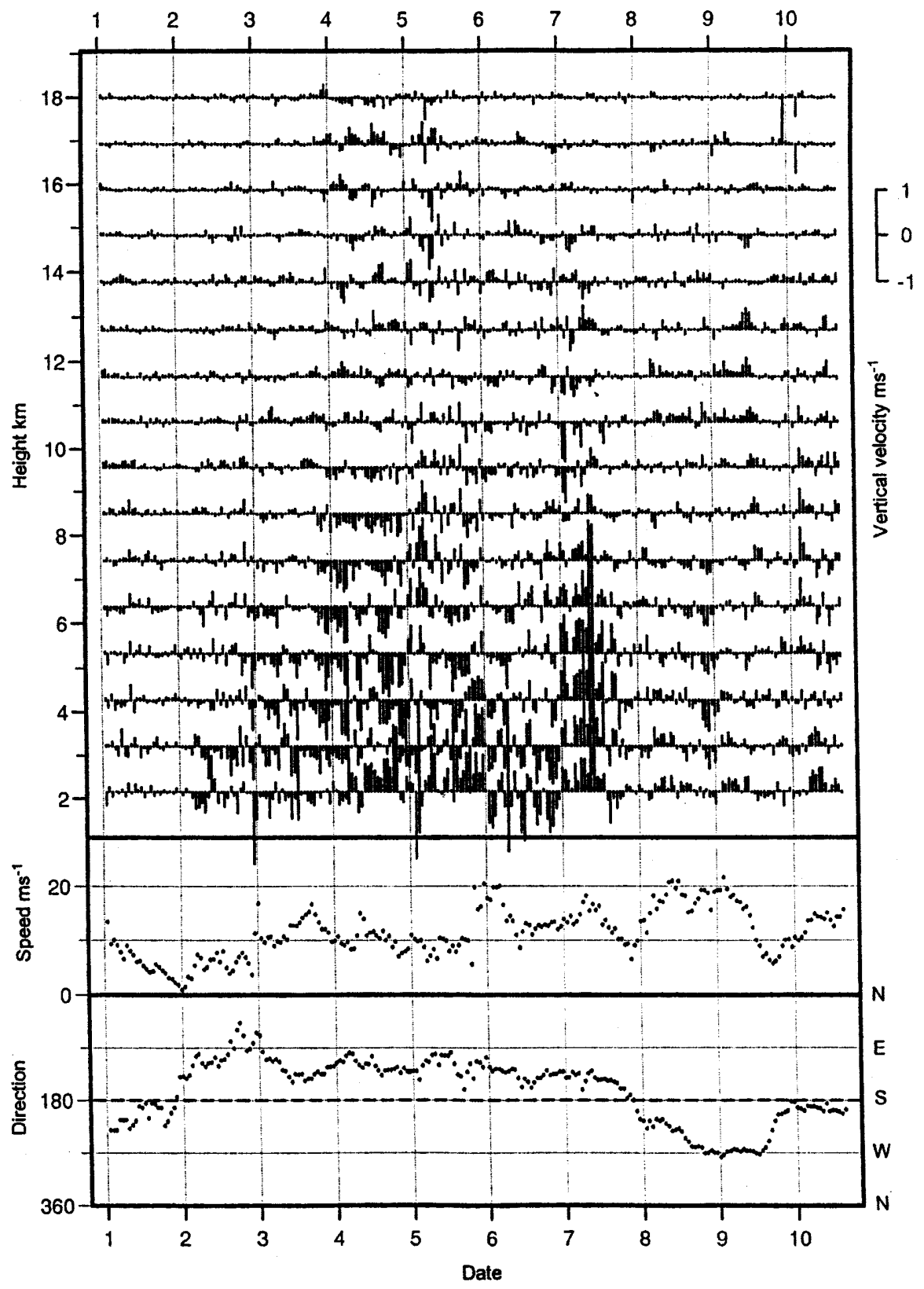

Fig. 6. Observations of mountain wave activity over Aberystwyth, Wales. Upper panel: hourly averages of velocity in the vertical antenna beam observed with the VHF radar. Lower panels: wind speed and direction at heights between $2.00 \mathrm{~km}$ and $2.75 \mathrm{~km}$ (from Prichard et al., 1995, Copyright Springer) lee waves rather than to longer period gravity waves (Rüster et al., 1998).

Temporal changes in the speed and direction of the air flow over mountainous terrain also change the spectrum of the generated gravity waves. The dependence of spectral density on frequency and its change with altitude is also very difficult to understand, since the generated waves interact with each other. For instance would longer period waves change $U$ and $N$ in Eq. (1), which affects the Scorer parameter 1 and this influences waves of other periods. The horizontal wave number $k_{h}$ of short-scale waves is in such cases no more negligible as compared to the Scorer parameter and the vertical wave number $k_{z}$. This means that the complete dispersion relation following from Eq. (2) or the vertical structure equation (Sharman and Wurtele, 1983; Ralph et al., 1992)

$$
\begin{gathered}
\mathrm{d}^{2} \mathbf{W} / \mathrm{d} z^{2}+\left(k_{x}^{2}+k_{y}^{2}\right) / k_{x}^{2} \cdot\left(N^{2} / U^{2}-k_{x}^{2} /\left(k_{x}^{2}+k_{y}^{2}\right)\right. \\
\left.\cdot 1 / U \mathrm{~d}^{2} U / \mathrm{d} z^{2}-k_{x}^{2}\right) \cdot \mathbf{W}=0
\end{gathered}
$$

have to be used to describe the waves and their spectrum. The velocity vector is $\mathbf{W}=\mathbf{W}\left(k_{x}, k_{y}, z\right)$, depending on the components of the horizontal wave vector $\mathbf{k}_{h}=\left(k_{x}, k_{y}\right)$. Since $U$ and $N$ are changed according to the amplitudes of all waves in the spectrum, it appears an unsolvable task to untangle this wave-wave interaction problem. Equations (1) and (3) are solvable for monochromatic and quasi-stationary waves. However, these cases may be rare in reality. Worthington and Thomas (1998) have shown that the vertical velocity usually follows a power law frequency spectrum rather than manifest a monochromatic signal, which would be expected for quasi-stationary lee waves. They conclude that the spectra represent a continuous, 


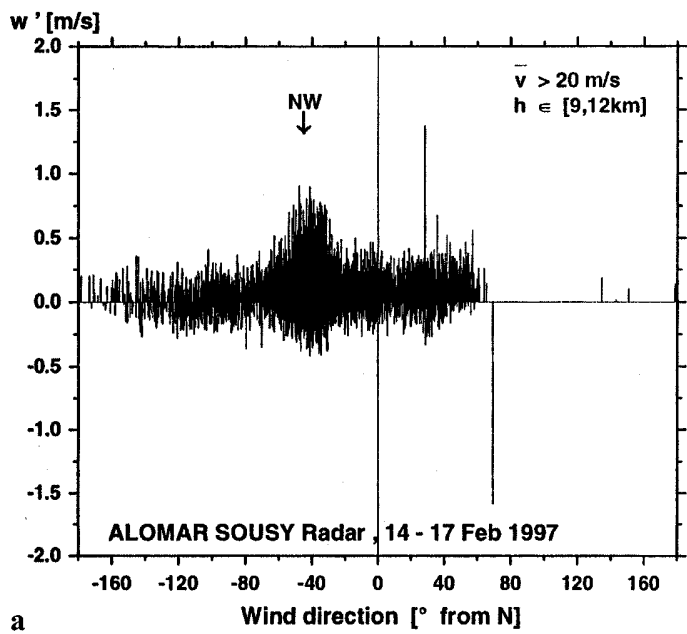

Fig. 7. a Dependence of vertical wind variations on the direction of the horizontal wind near the tropopause (9-12 km) observed 14-17 February, 1997, with the ALOMAR SOUSY radar in Norway (after

gradual change from steady, deterministic lee waves in the lowest frequency range, to an unsteady, nondeterministic component in the highest frequency range. While many of these results suggest that mountains generate freely propagating short-period waves, this does not indicate waves per se, since features of spatial phase modulation of topographically generated waves by the temporal variation of the background wind are noticed (Sato, 1990; Hines, 1995a). Nance and Durran (1997) have modeled this effect of irregular variations. The ST radar observations clearly prove the relation of atmospheric gravity wave activity with velocity and direction of winds blowing over mountainous terrain. Hines (1995b) concluded that freely propagating waves emerge from a fixed orography whenever the background winds are variable. This may contribute to the generation of a spectrum of waves propagating freely without the requirement that orographic waves must be stationary with respect to the ground.

Ralph et al. (1992) have discovered that a change of vertical velocity with time is a consequence of large horizontal gradients in the wind field, which accordingly requires three dimensional modeling of the wave features including the three-dimensional topography. Without needing multipoint observations, it was shown by Worthington (1999a) that the direction of the horizontal wave vector (azimuth) of mountain waves can be deduced by using the effect of tilted stable layers detected with VHF radar. This was done by using data from the Aberystwyth VHF radar in Wales (Slater et al., $1992)$ producing the vector from the power imbalance $[(P E-P W),(P N-P S)]$, where $P E$ is the power measured with the eastward pointing antenna beam $(P W$, $P N, P S$ correspondingly west-, north-, southward), or from the differences of averaged quasi-vertical velocities $[\langle W(P E-P W)\rangle,\langle W(P N-P S)\rangle]$. This approach applies only if the horizontal wavelength of the lee wave is at least three times as large as the antenna beam separation. It should be investigated whether the application of the spaced antenna interferometry and the post-beam-
Hoffmann et al., 1999). b Vertical wind as function of horizontal wind during January 1997 measured with the ESRAD radar in northern Sweden (after Rechou et al., 1997)

steering method (Röttger and Ierkic, 1985) would yield equivalent results, since these are measured in a smaller volume, just overhead the radar.

Worthington (1999b) analyzed data taken during 1990-1998 with the VHF radar at Aberystwyth in Wales, UK. He observed that the wind direction is more important for the wave alignment than the orientation of upstream mountain ridges. A significant difference between the wind and wave azimuth (Fig. 9) was found, which changes as function of height. It is concluded that the wave launching height is not at the surface but in the planetary boundary layer (below about $750 \mathrm{~m}$ ). The persistent offset of wind and wave azimuth above the launching height could be explained by wave stress due to friction, which could introduce a directional bias due to mountain wave drag of the wind in numerical models (Worthington, 1999b).

Caccia et al. (1997b) have analyzed lee wave activity detected by VHF ST radars at different locations. They also show that the kinetic energy in lee waves, given by the vertical velocity, depends on the upstream orography. The clear relation between the height of mountainous obstacles and vertical velocity variation can be used in numerical models of sub-grid scale processes. It is also pointed out by Caccia et al. (1997b) that vertical velocity fluctuations mix atmospheric constituents, and that this mixing can be estimated by knowing the wind direction and the local orography. It has to be considered here that mixing can be reversible for smallamplitude, non-breaking waves. This means that these fluctuations related to such waves should also be measured with radar.

The vertical propagation and the selection of prevalent lee or mountain wave modes depend critically on the height profile of the Scorer parameter (Eq. 1), which in turn depend on the horizontal phase speed of the waves. This interdependence makes an unambiguous conclusion on lee wave parameters very difficult as can be perceived by examining Eqs. (1) and (3). Nevertheless, some estimates can be obtained if there are 

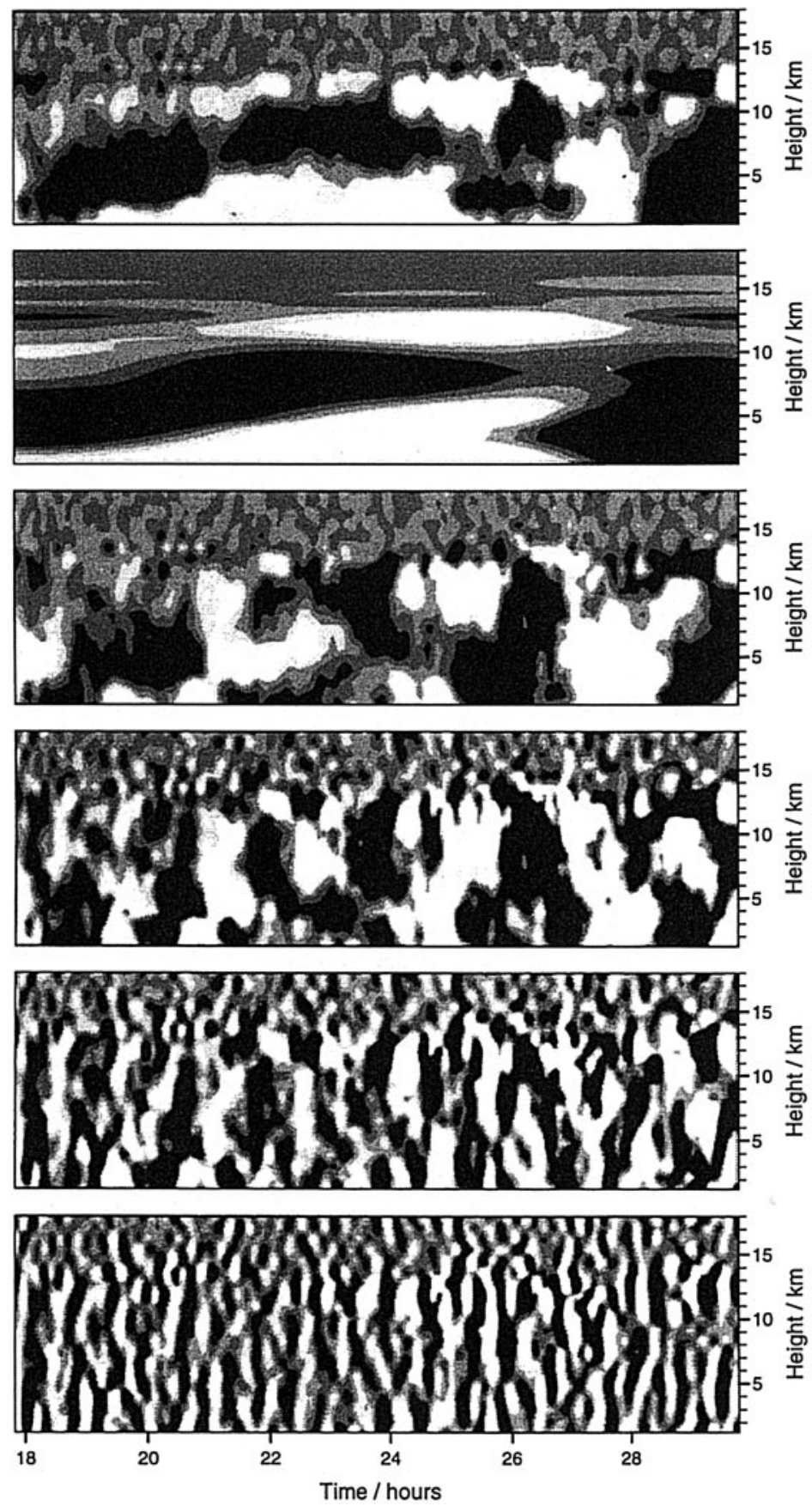

a) No filter

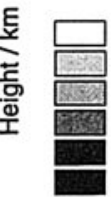

$$
\begin{array}{r}
\text { above } 0.40 \\
0.20-0.40 \\
-0.00-0.20 \\
-0.20--0.00 \\
-0.40--0.20 \\
\hline 0.06
\end{array}
$$

b) $>6$ hr, low-pass

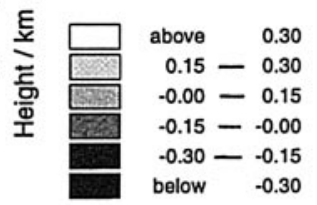

c) $<6 \mathrm{hr}$, high-pass

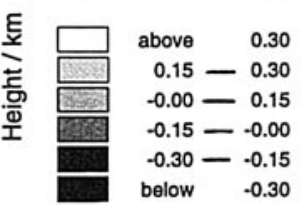

d) $<3 \mathrm{hr}$, high-pass

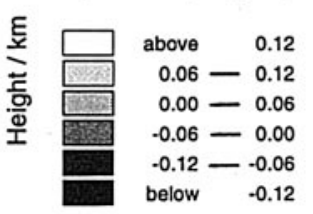

e) $<90 \mathrm{~min}$, high-pass

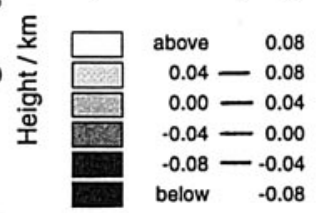

f) $<45 \mathrm{~min}$, high-pass

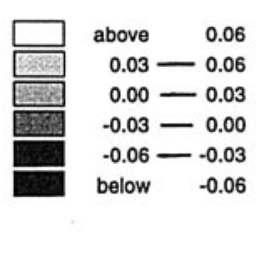

Fig. 8a-f. Height-time contour plots of velocity measured in the vertical beam with the Aberystwyth VHF radar, original and filtered time series (from Worthington and Thomas, 1998, Copyright Royal Met. Soc.) dominating waves. Figure 10 shows such profiles of the Scorer parameter calculated for vertically propagating and trapped wave events, which are quasi-stationary over several hours. Trapping or critical layer encountering near the tropopause can frequently be noticed in radar results, as concluded from the reduction in wave oscillations seen in Fig. 8 (Worthington and Thomas, 1998). However, Worthington and Thomas (1997) had also found large-amplitude lee wave events with very little phase change as function of height, which they do not attribute to trapping. They express that upward propagation of lee waves may often be affected in three stages: a minimum of the Scorer parameter in the upper troposphere, partial reflection at the tropopause and a critical layer when the wind velocity $U$ approaches the wave's phase velocity $c$ Eq. (1).

We would like to mention here that we should discriminate between the observations of quasi-stationary waves, which are usually called lee waves in the literature and shorter period, non-stationary waves (Ralph, 1997) which are also orographically generated and which are frequently called mountain waves. Whether such a discrimination of nomenclature has been applied consistently in the published literature and whether a separation into the terms lee waves (i.e., stationary long period waves) and mountain waves (i.e. non-stationary waves with periods shorter than several hours) is acceptable, remains to be discussed. 


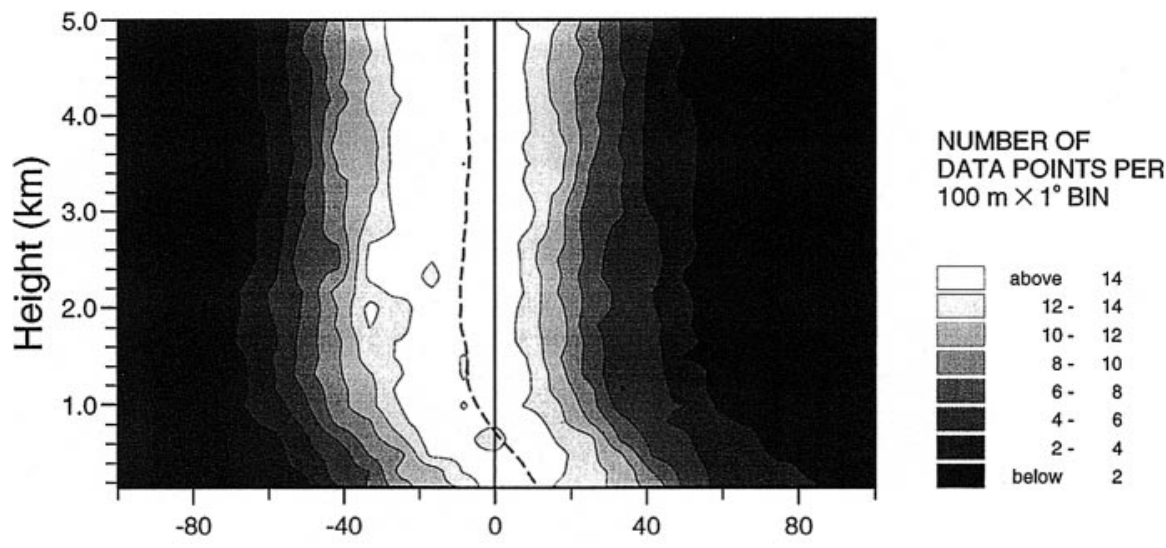

Difference between wind and wave azimuth (degrees)
Fig. 9. Difference between wind and wave azimuth in degrees measured over the Welsh mountains (from Worthington, 1999b, Copyright American Geophys. Union) (a)

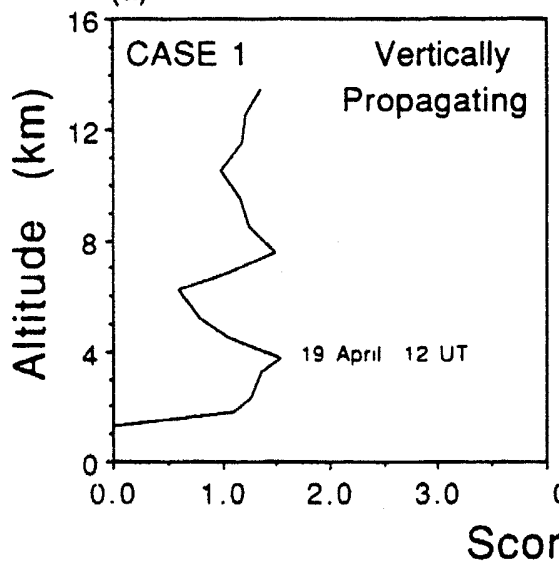

(b)

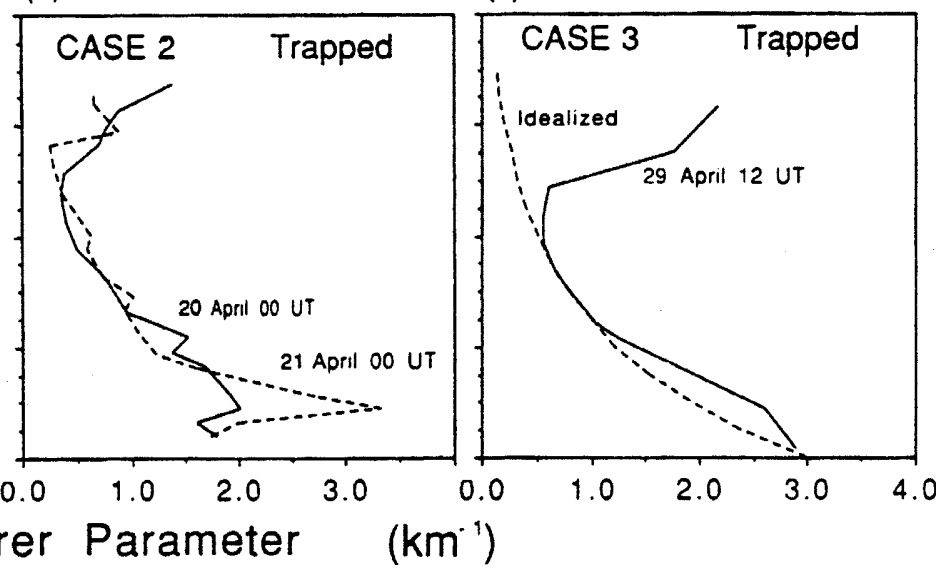

Fig. 10a-c. Vertical profiles of the Scorer parameter calculated from 3-6 h averaged profiles of VHF radar wind and radiosonde temperature (from Ralph et al., 1992, Copyright Royal Met. Soc.)

Admittedly, the wide spectrum of wave forms of erratic nature (Hines, 1995a) makes it quite difficult in frequent cases to choose the particular category and source of such waves. A suggestion would be anyway to use the term lee waves only when the waves are observed downwind, i.e., in the lee side of the mountain region.

\section{Mountain wave breaking and occurrence in the stratosphere}

Many VHF radar observations show strong mountain and lee wave amplitudes in the troposphere but frequently much smaller amplitudes are noticed in the stratosphere (Röttger et al., 1981; Ecklund et al., 1985; Prichard et al., 1995; Worthington and Thomas, 1996), where they may even be non existent (Worthington and Thomas, 1998). However, occasional events show clearly waves up to stratospheric heights (Ralph et al., 1992, Caccia et al., 1997a; Caccia, 1998). Prichard et al. (1995) mention that the existence of mountain waves in the stratosphere is strongly dependent on the nature of the tropopause. The height dependence of the Scorer parameter yields an explanation for this observation, since it frequently shows that the vertical wave number increases with height. This is a sign of waves, which are trapped or ducted in the troposphere, and consequently do not reach the stratosphere. Worthington and Thomas (1997a) have presented four convincing mountain wave events, where the phase remained about constant throughout the troposphere and partial reflection of the wave at the sharp temperature gradient of the tropopause prevented wave penetration into the stratosphere.

Also critical layers in the upper troposphere, where $U \rightarrow c$, may preclude propagation of these waves into the stratosphere as noted by Worthington and Thomas (1996), who report about absorption of mountain waves connected with enhanced turbulence. Worthington (1998) has described such a very clear event (Fig. 11). Strong wave oscillations abruptly cease at a level below the tropopause. At the same instance a thin layer of enhanced turbulence is observed by the radar at these heights (the width of the radar echo spectrum is a measure for turbulent velocities). It is surmised that mountain wave breaking causes this turbulence rather than shear in the upper tropospheric jet stream. Turbulence energy dissipation rates deduced from these observations let Worthington (1998) conclude that mountain wave breaking sometimes is the single most substantial source of turbulence in the lower 

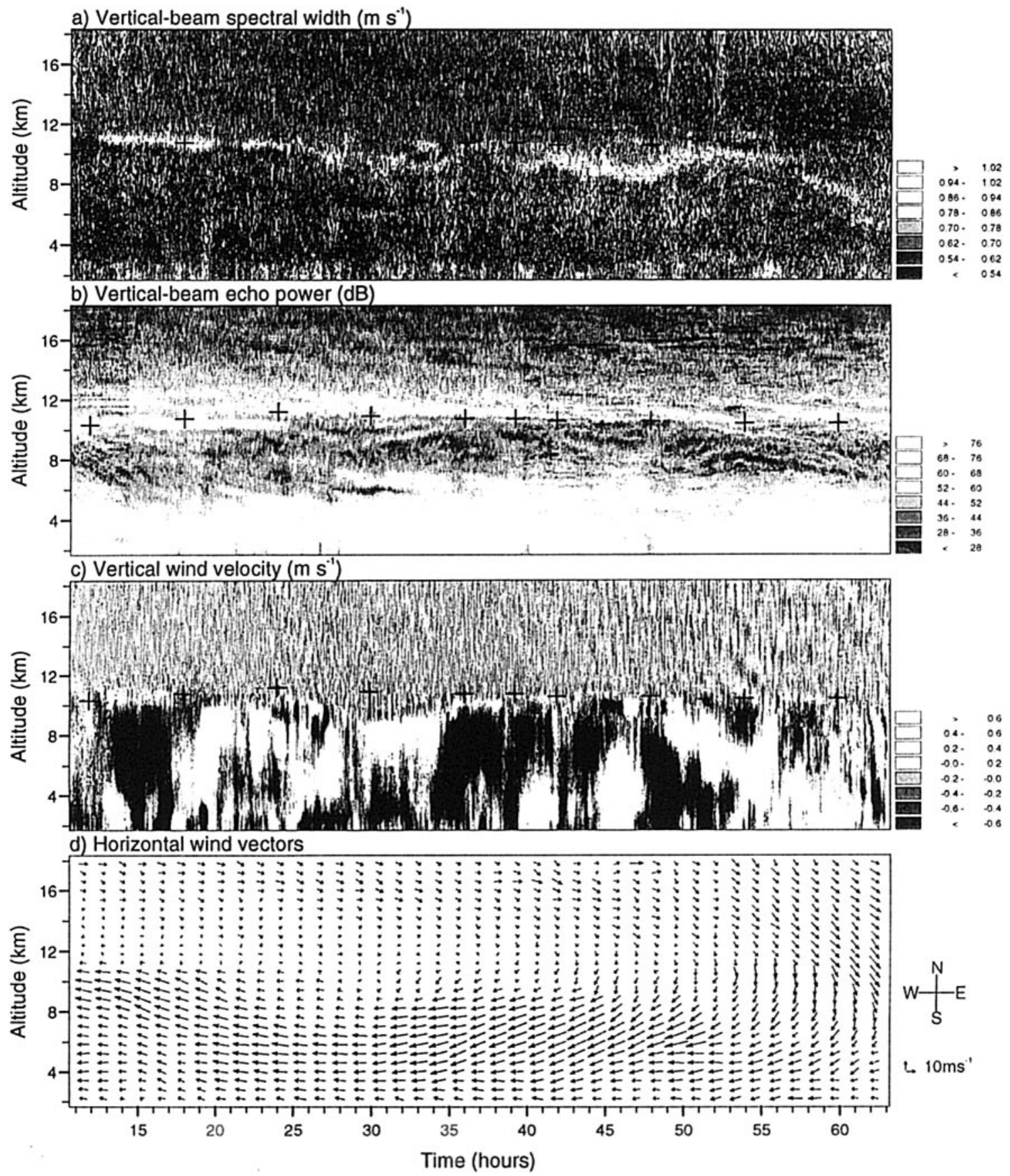

Fig. 11a-d. Height-time plots of (upper to lower panel): spectral width, echo power, vertical wind component, and horizontal wind vectors. The data were taken with the Aberystwyth VHF radar from 7

January, 1997, 10:30 UT, to 9 January, 1997, 15:10 UT (from Worthington, 1998, Copyright Elsevier)

atmosphere. Turbulence in the tropopause region can be an important factor for vertical mixing and transport of air masses. Critical level breaking of lee waves near the tropopause, thus, may be a dominant component in stratosphere-troposphere exchange, which is a highly relevant topic under study (Ebel, 1996).

The importance of mountain waves and the corresponding association with energy dissipation and momentum transfer by the associated turbulence was earlier noted by Lilly and Kennedy (1973), who deduced these quantities from aircraft measurements. VHF

radars had been frequently used for measuring the gravity wave momentum flux (Vincent and Reid, 1983) and energy dissipation rate (Hocking, 1985). Several investigations have been done on the capabilities and limitations of these radar measurements (Hocking, 1996; Worthington and Thomas, 1996; Kudeki and Franke, 1998). The effect of the momentum flux divergence of orographically generated gravity waves on the evolution of the general atmospheric circulation has been underlined by Palmer et al. (1986) and McFarlane (1987), and radars have contributed to obtain estimates of the flux 
divergence in the lower atmosphere (Fritts et al., 1990) and the middle atmosphere (Thorsen et al., 1997). Prichard and Thomas (1993), using data from the Aberystwyth VHF radar, expect that, because of the topography, orographic forcing would make a significant contribution to the short period gravity wave activity and the corresponding momentum flux. These authors presume that long-period motions are relatively more important in the troposphere and lower stratosphere than previously considered, and that it is likely that this depends on the location of the radar to the midlatitude jet stream. All these outcomes bring up the interesting questions whether orographically generated or jet stream generated waves, and whether long- or short-period waves are dominant.

\section{Lee waves and inertia-gravity waves}

Indications of long-period variations of velocity and radar reflectivity in the stratosphere have long been noticed in observations with VHF radar (Röttger, 1981b, Sato, 1994) and UHF radar (Cornish and Larsen, 1989). Such long-period variations have also been found in the mesosphere (Muraoka et al., 1989). Figure 12 shows a snapshot of a periodic height variation of the wind direction and vertical velocity in the stratosphere observed with the SOUSY-VHF-Radar, which is part of a longer data series. The horizontal wind vector rotated counterclockwise, the oscillation amplitude of the velocity $w$ increased with height and the periodic structure persisted over many hours. Since there is no similar oscillation noticed in the troposphere one is skeptic at whether such a clear variation can be caused by an orographically generated wave, i.e., a lee or mountain wave, which propagated into the middle atmosphere.

Sato (1994) has analyzed longer series of wind profiles measured with the MU radar in Japan, which show vertical progression of oscillations in the horizontal wind (Fig. 13). Applying a hodograph analysis one can determine essential wave parameters, such as intrinsic phase speed and horizontal wavelength. The hodo-
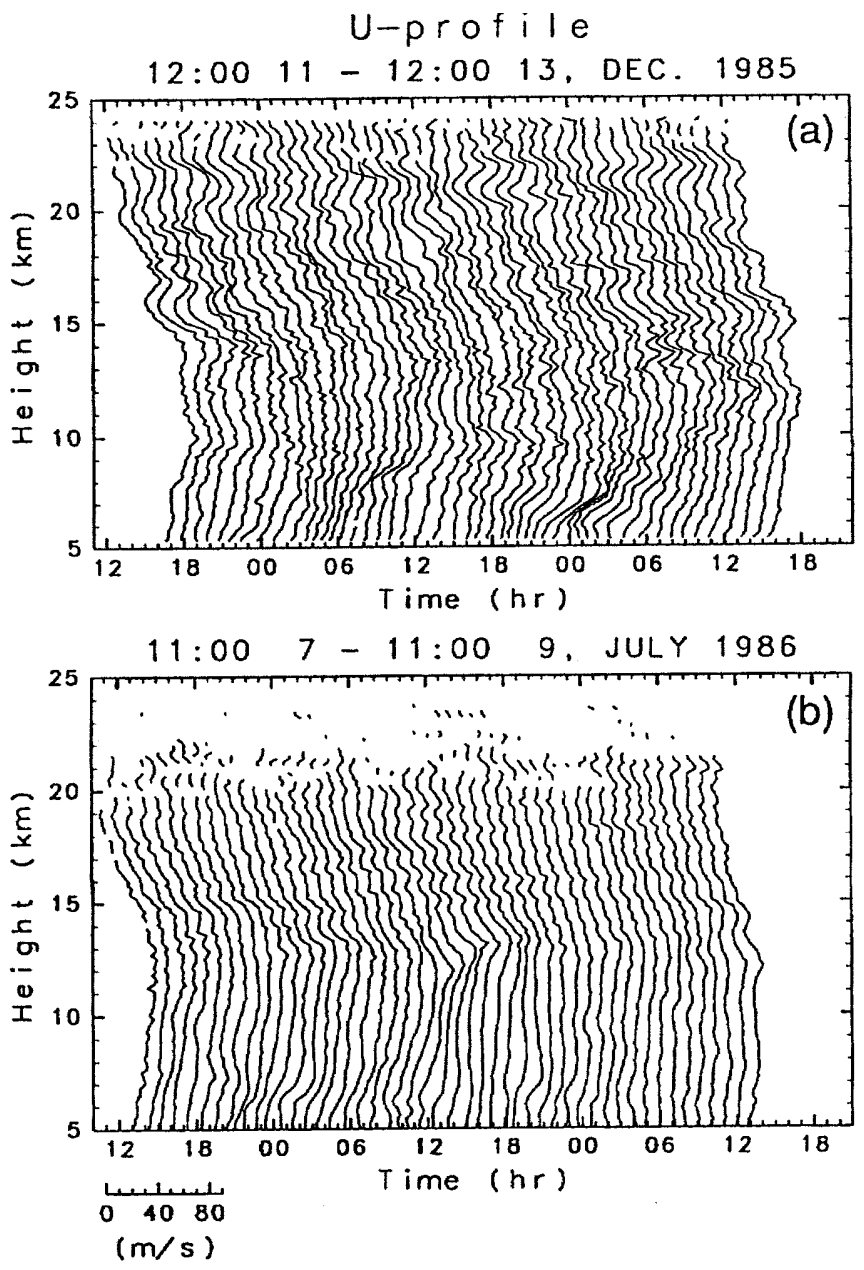

Fig. 13a, b. Time series of 1-h averaged vertical profiles of the horizontal wind component $U$ observed with the MU radar a in winter, and b in summer (from Sato, 1994, Copyright Elsevier)

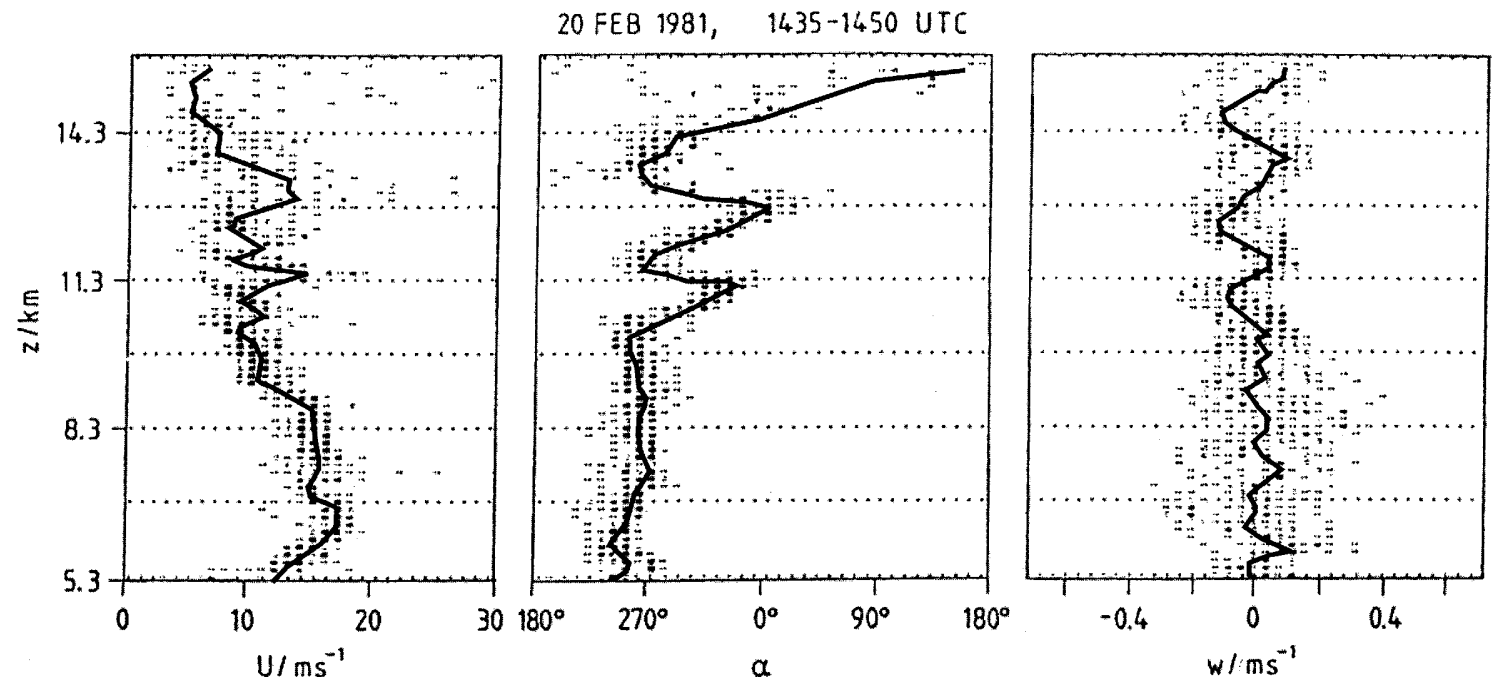

Fig. 12. Wind speed $U$, direction $\alpha$ and radial velocity $w$ in vertical beam showing wave oscillations in the lower stratosphere (after Röttger, 1984) 
graphs are affected by a vertical shear of the background wind, which had been taken into account and were further examined by Sato and Yamada (1994). The generation mechanism of these waves was found not to be geostrophic adjustment of the subtropical jetstream. Topographic forcing is not considered very likely either, but it was suggested that the waves observed in winter at $18-22 \mathrm{~km}$ height could possibly be due to lee waves.

Cornish and Larsen (1989) and Muraoka et al. (1989) found that inertia-gravity waves can explain the longperiod, short vertical wavelength perturbations of the wind in the stratosphere and mesosphere, respectively. Their interpretation based on the observation of long periods, short vertical wavelength and elliptical polarization of these waves. Hines (1989) was questioning this interpretation and claimed that lee waves with a relatively short intrinsic period could, in the presence of vertical shear in the horizontal wind, appear like internal gravity waves. In parallel to Hines (1995a, b, c) and Larsen (1995) discussing whether wind oscillations over the Arecibo Observatory, Puerto Rico, are due to lee or due to inertia-gravity waves (Cornish and Larsen, 1989), Cho (1995) analyzed those data using a cross-spectrum method applied to the zonal and meridional wind components. He proved that the vertical shear of horizontal wind is not large enough to account for the ellipticities of the hodographs, which are observed. Lee waves are by definition linearly polarized, which could only be changed by a vertical shear of the horizontal wind. Cho (1995) then deduced that the horizontal wind perturbation rotation observed in the stratosphere over Puerto Rico is caused by inertia-gravity waves rather than by lee waves embedded within a background vertical shear.

Most long-period stratospheric waves observed with the Aberystwyth VHF radar (Thomas et al., 1992, 1999), partially combined with lidar (McDonald et al., 1998), were interpreted to be inertia-gravity waves. The source of these waves was tentatively identified as the jetstream associated with synoptic scale disturbances. An evident proof for this seems to be that the hodographs of the horizontal perturbation velocity indicate downward energy flux in the troposphere and upward in the stratosphere (Thomas et al., 1999).

It is obvious, though, from other VHF ST radar observations (Ralph et al., 1992; Prichard et al., 1995) and from PSC observations (Fricke et al., 1998) that lee waves are also propagating into the stratosphere. This directly depends on the profile of the Scorer parameter, which indicates when a freely propagating or trapped wave would occur. In particular the thermal and dynamical structure in the tropopause region is a governing factor here. To study lee and mountain wave characteristics and their propagation and discrimination from other long-period waves, thus, needs the combination of measurements with radar and supplementary instruments such as lidar and passive optical systems as well as radiosondes or aircrafts. Combination with meso- and synoptic-scale observations and numerical models is very advisable here.
Long-period variations of vertical velocity and some relation to the structure of stratospheric radar reflectivity had been observed early with the SOUSY-VHFRadar (Röttger, 1981b) and explained by wind and temperature variations. Worthington and Thomas (1997) investigated in detail such long period wind variations and studied the resulting shear generation of turbulence layers. The latter could give rise to periodic structures of the radar reflectivity due to enhanced turbulence scatter or partial reflection from boundaries of these layers. It is unlikely, though not excluded, that lee or mountain waves cause such periodic structures in the radar reflectivity. Whether these waves are inertiagravity or lee waves is immaterial in this context, but it could give rise to the creation of stable sheets and laminae as described by Luce et al. (1995), which in turn could cause partial reflection of VHF radar signals.

\section{Conclusion}

It is popularly believed that lee waves are fairly stationary as visually observed through their appearance as lenticularis clouds. ST radar observations have substantially contributed to our understanding that besides such impressive quasi-stationary waves a broad spectrum of waves is often generated, which constitutes a major impact on lower and middle atmosphere dynamics. It may be difficult to cast a unified characteristic on this wide spectrum of topographically generated waves. The reason is that the terrain is usually very corrugated and the wind flowing over this terrain is notably variable in speed and direction at all spatial scales, partially due to turbulence in the boundary layer itself or due to the friction of the variable air flow with the irregular terrain. This mostly leads to a generation of a broad wave spectrum, where, however, amplitudes in certain frequency ranges could be preferred. Atmospheric filtering of such waves, which propagate vertically and horizontally, can also create significant amplitudes in some frequency ranges. The ST radars have observed this full spectrum of waves, including also fairly monochromatic events. This evidence is particularly pronounced due to the capability of the ST radars to measure also the vertical wind component. These events have been modeled using reasonable atmospheric parameters, which are obtained from the radar itself, such as the wind profiles, and from supplementary observations with radiosondes, lidars, aircraft and balloons.

The questions, which remain, are how is wave-wave interaction affecting the spectrum of these waves. How frequently can we assume that monochromatic and stationary waves dominate as compared to a spectrum of non-stationary waves? If and when inertia-gravity waves rather than lee or mountain waves are the reason for wave oscillations in the stratosphere, what is the generation mechanism of these waves, or vice versa? Can the generation by the jetstream, convective activity, and/or geostrophic adjustment compete against orographically generated waves? How is the distribution of this kind of wave activity over the globe and during different seasons 
and varying climate? Such large-scale global measurements are most appropriately done from space (Eckermann and Preusse, 1999). These observations show enhanced wave activity close to mountainous regions. We believe that ST radars can contribute further to these observations by providing vertical profiles, which will allow an easier discrimination between mountain waves and inertia-gravity waves. The latter had been reported to exist in the mesosphere (Muraoka, 1989), but nothing is known yet whether lee and mountain waves, or other wave activity created by these have been detected in these or higher altitudes. The existence of mountain or lee waves, propagated into the mesosphere and (thermosphere?), would be expected due to their large amplitude, which however could cause an earlier breaking at lower altitudes (Satomura and Sato, 1999).

We have summarized here the remarkable amount of impressive research work that has been performed on lee and mountain waves, their spectrum, the discrimination from other atmospheric waves and their sources and propagation. ST radars have and will continue to contribute efficiently to this research direction.

Acknowledgements. My thanks are directed to Tudor B. Jones and Geraint Vaughan for inviting me to contribute this paper to the special issue of Annales Geophysicae honoring Lance Thomas on the occasion of his 70th birthday. The provision of reprints and preprints by several colleagues were most helpful in preparing this review. I also thank the referees for valuable suggestions.

The Editor-in-chief thanks two referees for their help in evaluating this paper.

\section{References}

Bacmeister, J. T., Mountain-wave drag in the stratosphere and mesosphere inferred from observed winds and a simple mountain-wave parametrization scheme, J. Atmos. Sci., 50, 377-399, 1993.

Balsley, B. B., and D. A. Carter, Mountain waves in the tropical Pacific atmosphere: a comparison of vertical wind fluctuations over Pohnpei and Christmas Island using VHF wind profilers, J. Atmos. Sci., 46, 2698-2715, 1989.

Caccia, J. L., Lee wave vertical structure monitoring using heighttime analysis of VHF ST radar vertical velocity data, J. Appl. Meteorol., 37, 530-543, 1998.

Caccia, J. L., B. Benech, and V. Klaus, Space-time description of nonstationary trapped lee waves using ST radars, aircraft, and constant volume balloons during the PYREX experiment, J. Atmos. Sci., 54, 1821-1832, 1997a.

Caccia, J. L., M. Crochet, and K. Saada, ST radar evaluation of the standard deviation of the air vertical velocity perturbed by the local orography, J. Atmos. Solar-Terr. Phys., 59, 1127-1131, 1997b.

Cariolle, D., S. Müller, F. Cayla, and M. P. McCormick, Mountain waves, polar stratospheric clouds, and the ozone depletion over Antarctica, J. Geophys. Res., 94, 11 233-11 240, 1989.

Cho, J. Y. N., Inertio-gravity wave parameter estimation from cross-spectral analysis, J. geophys. Res., 100, 18 727-18 737, 1995.

Cornish, C. R., and M. F. Larsen, Observations of low-frequency gravity waves in the lower stratosphere over Arecibo, J. Atmos. Sci., 46, 2428-2439, 1989.

Czechowsky, P., and R. Rüster, VHF radar observations of turbulent structures in the polar mesopause region, Ann. Geophysicae, 15, 1028-1036, 1997.
De Rudder, A., N. Larsen, X. Tie, G. P. Brasseur, and C. Granier, Model study of polar stratospheric clouds and their effect on stratospheric ozone, 1. Model description, J. Geophys. Res., 101, 12 567-12 574, 1996.

Dieminger, W., G. K. Hartmann, and R. Leitinger, eds., The upper atmosphere, Springer, Berlin Heidelberg New York, 1996.

Ebel, A., Stratosphere-troposphere exchange and its impact on the structure of the lower stratosphere, J. Geomagn. Geoelectr., 48, 135-144, 1996.

Eckermann, S. D., and P. Preusse, Global measurements of stratospheric mountain waves from space, Science, 286, 1534 1537, 1999.

Ecklund, W. L., K. S. Gage, and A. C. Riddle, Gravity wave activity in vertical winds observed by the Poker Flat MST radar, Geophys. Res. Lett., 8, 285-288, 1981.

Ecklund, W. L., K. S. Gage, B. B. Balsley, R. G. Strauch, and J. L. Green, Vertical wind variability observed by VHF radar in the lee of the Colorado Rockies, Mon. Weather Rev., 110, 14511457, 1982.

Ecklund, W. L., B. B. Balsley, D. A. Carter, A. C. Riddle, M. Crochet, and R. Garello, Observations of vertical motions in the troposphere and lower stratosphere using three closely spaced ST radars, Radio Sci., 20, 1196-1206, 1985.

Enell, C. F., A. Steen, T. Wagner, U. Frieß, K. Pfeilsticker, U. Platt, and K. H. Fricke, Occurrence of polar stratospheric clouds at Kiruna, Ann. Geophysicae, 17, 1457-1462, 1999.

Fricke, K. H., K. P. Müller, M. Serwazi, J. Reichardt, S. Kirkwood, A. Steen, P. Hoffmann, H. Mehrtens, A. Hauchecorne, F. Fierli, U. P. Hoppe, and G. Hansen, Observations of dynamically induced polar stratospheric clouds in the lee of the Scandinavian mountain ridge, Proc. Europ. Workshop Mesoscale Processes in the Stratosphere, 1998.

Fritts, D. C., and P. K. Rastogi, Convective and dynamical instabilities due to gravity wave motions in the lower and middle atmosphere: theory and observations, Radio Sci., 20, 1247-1277, 1985.

Fritts, D. C., and G. D. Nastrom, Sources of mesoscale variability of gravity waves. Part II: frontal, convective, and jet stream excitation, J. Atmos. Sci., 49, 111-127, 1992.

Fritts, D. C., T. Tsuda, T. E. VanZandt, S. A. Smith, T. Sato, S. Fukao, and S. Kato, Studies of velocity fluctuations in the lower atmosphere using the MU radar, II, Momentum fluxes and energy densities, J. Atmos. Sci., 47, 51-66, 1990.

Hansen, G., and U. P. Hoppe, Lidar observations of polar stratospheric clouds and stratospheric temperature in winter 1995/96 over Northern Norway, Geophys. Res. Lett., 24, 131-134, 1997.

Hines, C. O., Tropopausal mountain waves over Arecibo: a case study, J. Atmos. Sci., 46, 476-488, 1989.

Hines, C. O., Modulated mountain waves, J. Atmos. Sci., 52, 602-606, 1995a.

Hines, C. O., Comments on "Observations of low-frequency inertia-gravity waves in the lower stratosphere over Arecibo", J. Atmos. Sci., 52, 607-610, 1995b.

Hines, C. O., Reply, J. Atmos. Sci., 52, 613, 1995c.

Hocking, W. K., Measurement of turbulent energy dissipation rates in the middle atmosphere by radars, Radio Sci., 20, 1403-1422, 1985.

Hocking, W. K., An assessment of the capabilities and limitations of radars in measurements of upper atmospheric turbulence, Adv. Space Res., 17, (11)37-(11)47, 1996.

Hocking, W. K., Strengths and limitations of MST radar measurements of middle-atmospheric winds, Ann. Geophysicae, 15, 1111-1122, 1997a.

Hocking, W. K., Recent advances in radar instrumentation and techniques for studies of the mesosphere, stratosphere, and troposphere, Radio Sci., 32, 2241-2270, 1997b.

Hoffmann, P., W. Singer, D. Keuer, and K. Schulz-Schoellhammer, Observations of $3 \mathrm{D}$ winds and waves in the tropopause region above northern Norway with the ALOMAR SOUSY Radar during winter 1996/97, Proc. European Workshop on Mesoscale Phenomena in Stratosphere, 1999. 
Kudeki, E., and S. J. Franke, Statistics of momentum flux estimation, J. Atmos. Solar-Terr. Phys., 60, 1549-1553, 1998.

Lafaysse, C., Ed., Utilization of UHF/VHF radar wind profiler networks for improving weather forecasting in Europe, COST 74 Final Rep., European Commission, Brussels, 1994.

Larsen, M. F., Reply to comments on "modulated mountain waves", J. Atmos. Sci., 52, 611-612, 1995.

Leutbecher, M., and H. Volkert, Stratospheric temperature anomalies and mountain waves: A three-dimensional simulation using a multi-scale weather prediction model, Geophys. Res. Lett., 23, 3329-3332, 1996.

Lilly, D. K., and P. J. Kennedy, Observation of stationary mountain wave and its associated momentum flux and energy dissipation, J. Atmos. Sci., 41, 1135-1152, 1973.

Liziola, L. E., and B. B. Balsley, Horizontally propagating quasisinusoidal tropospheric waves observed in the lee of the Andes, Geophys. Res. Lett., 24, 1075-1078, 1997.

Luce, H., M. Crochet, F. Dalaudier, and C. Sidi, Interpretation of VHF ST radar vertical echoes from in-situ temperature sheet observations, Radio Sci., 30, 1003-1025, 1995.

McDonald, A. J., L. Thomas, and D. P. Wareing, Night-to-nightchanges in the characteristics of gravity waves at stratospheric and lower-mesospheric heights, Ann. Geophysicae, 16, 229-237, 1998.

Mehrtens, H., G. von Cossart, A. Hauchecorne, and F. Fierly, Polar stratospheric clouds observed by the ALOMAR Rayleigh/Mie Raman lidar and the temperature field above Andoya, Proc. 13th ESA Symp., ESA SP-397, 163-167, 1997.

Mitchell, N. J., L. Thomas, and I. T. Prichard, Gravity waves in the stratosphere and troposphere observed by lidar and MST radar, J. Atmos. Terr. Phys., 56, 939-947, 1994.

Muraoka, Y., T. Sugiyama, T. Sato, T. Tsuda, S. Fukao, and S. Kato, Interpretation of layered structure in mesospheric VHF echoes induced by an inertia gravity wave, Radio Sci., 24, 393406, 1989.

Nance, L. B., and D. R. Durran, A modelling study of nonstationary trapped mountain lee waves. Part I: mean-flow variability, J. Atmos. Sci., 54, 2275-2291, 1997.

Nastrom, G. D., D. C. Fritts, and K. S. Gage, An investigation of terrain effects on the meso-scale spectrum of atmospheric motions, J. Atmos. Sci., 44, 3087-3096, 1987.

Nastrom, G. D., M. R. Peterson, J. L. Green, K. S. Gage, and T. E. VanZandt, Sources of gravity wave activity seen in the vertical velocities observed by the Flatland VHF radar, J. Appl. Meteorol., 25, 783-792, 1990.

Nastrom, G. D., and D. C. Fritts, Sources of mesoscale variability of gravity waves. Part I: topographic excitation, J. Atmos. Sci., 49, 101-110, 1992.

Palmer, T. N. G., J. Shutts, and R. Swinbank, Alleviation of a systematic westerly bias in general circulation and numerical weather prediction models through an orographic gravity wave drag parametrization, $Q . J$. R. Meteorol Soc., 112, 1001-1040, 1986.

Prichard, I. T., and L. Thomas, Radar observations of gravity-wave momentum fluxes in the troposphere and lower stratosphere, Ann. Geophysicae, 11, 1075-1083, 1993.

Prichard, I. T., L. Thomas, and R. M. Worthington, The characteristics of mountain waves observed by radar near the west coast of Wales, Ann. Geophysicae, 13, 757-767, 1995.

Ralph, F. M., M. Crochet, and V. Venkateswaran, A study of mountain lee waves using clear-air radar, Q. J. R. Metorol. Soc., 118, 597-627, 1992.

Ralph, F. M., Observation, simulations, and analysis of nonstationary trapped lee waves, J. Atmos. Sci., 54, 1308-1333, 1997.

Rechou, A., V. Barabash, P. Chilson, S. Kirkwood, S. Savitskaya, and K. Stebel, ESRAD MST radar analysis of waves, Proc. 4th European Symposium Stratospheric Ozone, September 1997.

Rechou, A., V. Barabash, P. Chilson, S. Kirkwood, S. Savitskaya, and K. Stebel, The influence of synoptic weather systems on vertical propagation of lee waves, Ann. Geophysicae, in press, 2000
Rechou, A., V. Barabash, P. Chilson, S. Kirkwood, T. Savitskaya, and K. Stebel, Mountain wave motions determined by the Esrange MST radar, Ann. Geophysicae, 17, 957-970, 1999.

Röttger, J., Wind variability in the stratosphere deduced from spaced antenna measurements, Proc. 20th Conference on Radar Meteorology, American Meteorological Society, 22-29, 1981a.

Röttger, J., The dynamics of stratospheric and mesospheric fine structure investigated with an MST VHF radar, Proc. Middle Atmos. Progr., Handbook for MAP, SCOSTEP, 2, 341-350, $1981 b$.

Röttger, J., Investigations of lower and middle atmosphere dynamics with spaced antenna drifts radars, J. Atmos. Terr. Phys., 43, 277-292, 1981c.

Röttger, J., Vertical transport in the atmosphere - Measurement capabilities and requirements of VHF radars, Proc. URSI/ SCOSTEP Workshop Techn. Aspects MST Radar, Handbook for MAP, SCOSTEP, 14, 49-57, 1984.

Röttger, J., Radar investigations of the mesosphere, stratosphere and the troposphere over Svalbard, Advances in Polar Upper Atmosphere Research, National Inst. Polar Res., Japan, accepted, 2000.

Röttger, J., and P. Czechowsky, Tropospheric and stratospheric wind measurements with the spaced antenna drift technique and the Doppler beam swing technique using a VHF radar, Proc. 19th Conf. Radar Meteorology, American Meteorological Society, 577-584, 1980.

Röttger, J., and H. M. Ierkic, Postset beam steering and interferometer applications of VHF radars to study winds, waves and turbulence in the lower and middle atmosphere, Radio Sci., 20, 1461-1480, 1985.

Röttger, J., T. Y. Kang, and M. Y. Zi, Mountain lee waves detected in radar wind profiles, $M P A e-W-00-81-36$, Max-Planck-Institut für Aeronomie, pp 19, 1981.

Röttger, J., and M. F. Larsen, UHF/VHF radar techniques for atmospheric research and wind profiler applications, Radar Meteorology, American Meteorological Society, 235-281, 1990.

Röttger, J., C. H. Liu, J. K. Chao, A. J. Chen, C. J. Pan, and I-J. Fu, Spatial interferometer measurements with the Chung-Li VHF radar, Radio Sci., 25, 503-515, 1990.

Rüster, R., G. D. Nastrom, and G. Schmidt, High-resolution VHF radar measurements in the troposphere with a vertically pointing beam, J. Appl. Meteorol., 37, 1522-1529, 1998.

Sato, K., A statistical study on structure, saturation and sources of inertio-gravity waves in the lower stratosphere observed by the MU radar, J. Atmos. Terr. Phys., 56, 755-774, 1994.

Sato, K., and M. Yamada, Vertical structure of atmospheric gravity waves revealed by the wavelet analysis, J. Geophys. Res., 99, $20623-20631,1994$.

Satomura, T., and K. Sato, Secondary generation of gravity waves associated with the breaking of mountain waves, J. Atmos. Sci., 56, 3874-3858, 1999.

Schlüter, M., Untersuchung von Leewellen im Harz mit Hilfe von Radardaten, Thesis, Institut Meteorologie und Klimatologie, Universität Hannover, pp 82, 1993.

Scorer, R. S., Environmental aerodynamics, John Wiley, London, England, 1978.

Scorer, R. S., Dynamics of meteorology and climate, John Wiley, Chichester, England, 1997.

Sharman, R. D., and M. G. Wurtele, Ship waves and lee waves, J. Atmos. Sci., 40, 418-427, 1983.

Slater, K., A. D. Stevens, S. A. M. Pearman, D. Eccles, A. J. Hall, R. G. T. Bennet, L. France, G. Roberts, Z. K. Olewicz, and L. Thomas, Overview of the MST radar system at Aberystwyth, Proc. 5th Workshop Techn. Scient. Aspects MST Radar, Aberystwyth, UK, STEP Handbook, SCOSTEP, 479-482, 1992.

Smith, R. B., The influence of mountains on the atmosphere, $A d v$. Geophys., 21, 87-230, 1979.

Stebel, K., and S. Kirkwood, MST radar study of lee waves during winter 1996/97, 97/98 and 98/99 in northern Scandinavia, Proc. 14th ESA Symp. SP-437, 309-313, 1999. 
Stebel, K., P. Chilson, V. Barabash, S. Kirkwood, A. Rechou, T. Savitskaya, P. Hoffmann, W. Singer and G. Schmidt, MSTradar lee wave observations during winter 1996/97 in northern Scandinavia, Proc.13th ESA Symp., ESA SP-397, 179-183, 1997.

Sun, W. Y., and J. D. Chern, Diurnal variation of lee vortices in Taiwan and the surrounding area, J. Atmos. Sci., 50, 34043430, 1993.

Takayabu, I., H. Niino, M. D. Yamanaka, and S. Fukao, An observational study of cyclogenesis in the lee of the Japan central mountains, Meteorol. Atmos. Phys., 61, 39-53, 1996.

Thomas, L., I. T. Prichard, and I. Astin, Radar observations of an inertia-gravity wave in the troposphere and lower stratosphere, Ann. Geophysicae, 10, 690-697, 1992.

Thomas, L., R. M. Worthington, and A. J. McDonald, Inertiagravity waves in the troposphere and lower stratosphere associated with a jetstream exit region, Ann. Geophysicae, 17, 115-121, 1999.

Thorsen, D., S. J. Franke, and E. Kudeki, HF Doppler measurements of mesospheric gravity wave momentum fluxes, Radio Sci., 32, 707-726, 1997.

Tie, X., G. P. Brasseur, C. Granier, A. De Rudder, and N. Larsen, Model study of polar stratospheric clouds and their effect on stratospheric ozone, 2. Model results, J. Geophys. Res., 101, 12 575-12 584, 1996.

Van Baelen, J. S., A. D. Richmond, R. T. Tsuda, and S. K. Avery, Radar interferometry technique and anisotropy of the echo power distribution: first results, Radio Sci., 26, 1315-1326, 1991.
Vincent, R. A., and I. M. Reid, HF Doppler measurements of mesospheric gravity wave momentum fluxes, J. Atmos. Sci., 40, 1321-1333, 1983.

Woodman, R. F., and A. Guillen, Radar observations of winds and turbulence in the stratosphere and mesosphere, J. Atmos. Sci., 31, 493-505, 1974.

Worthington, R. M., Tropopausal turbulence caused by breaking of mountain waves, J. Atmos. Solar-Terr. Phys., 60, 1543-1547, 1998.

Worthington, R. M., Calculating the azimuth of mountain waves, using the effect of tilted fine-scale stable layers on VHF radar echoes, Ann. Geophysicae, 17, 257-272, 1999a.

Worthington, R. M., Alignment of mountain wave patterns above Wales: a VHF radar study during 1990-1998, J. Geophys. Res., 104, 9199-9212, 1999b.

Worthington, R. M., and L. Thomas, The measurement of gravity wave momentum flux in the lower atmosphere, Radio Sci., 31, 1501-1517, 1996.

Worthington, R. M., and L. Thomas, Impact of the tropopause on upward propagation of mountain waves, Geophys. Res. Lett., 24, 1071-1074, 1997a.

Worthington, R. M., and L. Thomas, Long-period gravity-waves and associated VHF radar echoes, Ann. Geophysicae, 15, 813-822, $1997 b$.

Worthington, R. M., and L. Thomas, The frequency spectrum of mountain waves, Q. J. R. Meteorol. Soc., 124, 687-703, 1998.

Worthington, R. M., R. D. Palmer, and S. Fukao, An investigation of tilted aspect-sensitive scatterers in the lower atmosphere using the MU and Aberythwyth VHF radars, Radio Sci., 34, 413-426, 1999. 